\title{
Distribution of Growth Hormone-Release-Inhibiting Hormone (Somatostatin) in the Rat Brain as Observed with Immunocytochemistry ${ }^{1}$
}

\author{
BURTON L. BAKER AND YA-YEN YU ${ }^{2}$ \\ Department of Anatomy and Reproductive Endocrinology Program, \\ The University of Michigan Medical School, \\ Ann Arbor, Michigan 48104
}

\begin{abstract}
The objective was to determine the distribution of growth hormone-release-inhibiting hormone (somatostatin) in the rat brain using the peroxidase-antiperoxidase immunocytochemical method with antisera prepared against unconjugated, synthetic somatostatin. Somatostatin occurred in low quantity in the organum vasculosum of the lamina terminalis. It was present throughout the full length of the median eminence and occupied the entire width between the tuberoinfundibular sulci. Most somatostatin was located in the dorsal portion of the external lamina, and the amount varied according to the mediolateral position. The bodies labeled for somatostatin were most of ten granules; occasionally they appeared as clusters of granules that seemed to be membraneenclosed. Some of these bodies appeared to be portions of axons. Many of the larger bodies were arranged alongside tanycytes, but no label was distributed generally in tanycyte cytoplasm. Somatostatin was highly concentrated in the proximal one-quarter of the infundibular stem and appeared in lower concentration throughout the distal portion of the stem. It was absent from the pars nervosa and pars intermedia of the pituitary gland. The distribution of somatostatin in the median eminence differed considerably from that of gonadotropinreleasing hormone.

Somatostatin was identified in the ventromedial and/or dorsomedial hypothalamic nuclei of only two animals. Here it was probably located in axons that terminated on neuronal cell bodies but also may have been present in a restricted portion of the perikaryonal cytoplasm.
\end{abstract}

Research on hypothalamic control of the endocrine system would be facilitated if one could identify the sites in the brain where hypophysiotropic hormones are synthesized and secreted. Recent determination of the chemical structure of growth hormone-release-inhibiting hormone (somatostatin) by Brazeau et al. (73) made possible the synthesis and availability of this hormone in pure form. As a result, precise studies on the tissue distribution of somatostatin became possible based on immunocytochemical and radioimmunoassay procedures. Hökfelt et al. ('74) and Dubé et al. ('75) have described the localization of somatostatin in the guinea pig brain as revealed by immunofluorescence and immunocytochemistry, respectively. Also, Pelletier et al. ( 74,75$)$ in brief communications, King et al. (75) and Hökfelt et al. ('75) have reported on the localization of somatostatin in the rat brain as observed by light and/or electron microscopic immunocytochemistry. Comparison of these reports with those derived from the use of radioimmunoassay (Brownstein et al., '75; Patel et al., '75) reveals significant discrepancies in descriptions of the distribution of somatostatin in the body. Hence, in this paper we report our observations on immunocytochemical localization of somatostatin in the rat brain. For our investigation antisera were prepared against synthetic somatostatin; for all other reported studies, antibodies were

Received Nov. 14, '75. Accepted May 18, '76.

1 Supported in part by a Program Project Grant (HD-08333) directed by Dr. A. R. Midgley, Jr, from the National Institute for Child Health and Human Development.

2 We thank Rosalie Proulx and Frances Wicks for their technical assistance. 
raised against somatostatin conjugated with a protein.

\section{MATERIALS AND METHODS}

The subjects were 21 female and 6 male, young adult Sprague-Dawley rats. Their mean body weights were $252 \pm 6 \mathrm{gm}$ (s.e.m.) for the females and $323 \pm 18 \mathrm{gm}$ for the males. After decapitation, the superior part of the cranium was removed and the ventral surface of the brain rapidly exposed. During subsequent dissection, the brain was flooded with the fixative, Bouin's fluid. In order to ensure optimal preservation, a median block of tissue encompassing the hypothalamus was removed from the brain. The boundaries of this block were as follows: sagittal planes based on the optic tracts; caudally a transverse plane through the interpeduncular fossa; a transverse plane anterior to the optic chiasma; and a frontal plane superior to the anterior and posterior cerebral commissures. In some cases the hypophysis and epiphysis were removed and fixed separately. Fixation by immersion in Bouin's fluid continued for 24 to 48 hours. After embedding in Paraplast, the brain blocks were sectioned transversely at $3-5 \mu \mathrm{m}$; a few were cut sagittally. Every fortieth section was stained with cresyl violet to facilitate identification of hypothalamic nerve cell nuclei and selection of sections for immunocytochemical labeling.

For immunocytochemistry the peroxidase-antiperoxidase (PAP) method was employed essentially as described originally by Sternberger et al. ('70) and subsequently modified by Petrali et al. ('74). 3,3'-Diaminobenzidine (DAB) served as the electron donor and label for somatostatin. From every block of hypothalamus that was sectioned transversely, immunocytochemical labeling was carried out on one or more sections from levels that contained the following structures: the medial septal nucleus; organum vasculosum of the lamina terminalis (OVLT); optic chiasm and suprachiasmatic nucleus; anterior end of the median eminence; broad central segment of the median eminence; the junction of the infundibulum and median eminence; median eminence just caudal to this junction; and the floor of the inframammillary recess.
The cyclic form of synthetic somatostatin ${ }^{3}$ was used in the preparation of antisera; however, data are not available that verify the purity of the somatostatin preparation used as the antigen. Immunization was carried out by the method of Vaitukaitis et al. ('71) in rabbits weighing 3-4 kg. The following pertinent antisera were obtained. B173 was employed routinely at a dilution of $1 / 50$ and, unless stated to the contrary, preparations labeled with it served as the basis for localization of somatostatin. With antiserum B173, somatostatin was detected in the median eminence-infundibular stem of all rats and, in a few cases, in association with certain nerve cell bodies of the hypothalamus. The specificity of this antiserum was demonstrated readily by loss of its immunological effectiveness after prior absorption with somatostatin (figs. 10, 11). Several other antisera were obtained that stained nerve cell perikarya and nerve fibers in the ventromedial and dorsomedial hypothalamic nuclei of all rats while being ineffective for demonstration of somatostatin in the median eminence. Of these antisera, B184 was studied intensively. Prior absorption of this antiserum with somatostatin did not prevent subsequent staining of these hypothalamic nuclei even though a maximal dilution of the antiserum and maximal concentration of somatostatin were used in the absorption. Therefore, this staining was regarded as non-specific even though the distribution of oxidized DAB in association with cell bodies and axons was similar to that obtained with B173.

The specificity of $\mathrm{B} 173$ was supported by the following additional control procedures. No labeling was obtained if normal rabbit serum was substituted for the primary antiserum. Also, labeling of somatostatin in the median eminence continued after prior absorption of B173 with some hypothalamic substances, including gonadotropin-releasing hormone (GnRH), thyrotropin-releasing hormone (TRH), vassopressin and oxtocin (table 1). A minor cross-reaction between somatostatin and

3 Somatostatin was obtained from Bachem, Inc., 4077 Glencoe Ave, Marina Del Rey, California 90291. We thank Dr. L. A. Sternberger for providing the soluble peroxidase-antiperoxidase (PAP) complex. Oxytocin, vasopressin, and TRH were obtained from Beckman Instruments, Inc., Bioproducts Department. 
TABLE 1

The amount of somatostatin labeled in the median eminence after prior absorption with hypothalamic substances

\begin{tabular}{|c|c|c|c|c|c|c|}
\hline \multicolumn{7}{|c|}{ Absorbant 1} \\
\hline & PBS & $\begin{array}{l}\text { Somato- } \\
\text { statin }\end{array}$ & GnRH & TRH & $\begin{array}{c}\text { Vaso- } \\
\text { pressin }\end{array}$ & Oxytocin \\
\hline
\end{tabular}
$1 / 50$

$11 \%$ solutions of the absorbants were mixed 1:1 with anti-sumatostatin B173 (1/50) and incubated overnight.

2 The amount of somatostatin labeled was rated " 0 " to " 4 ," "4" indicating the amount observed after mixture of anti-somatostatin with physiological buffered saline (PBS).

GnRH was indicated. It was not considered significant because of its small magnitude and the different localizations demonstrated for the two hormones.

Because of the variable concentrations and distributions of somatostatin across the median eminence, description of its localization will be facilitated by subdividing the median eminence into five longitudinal zones (fig. 1). When viewed in a transverse plane at its widest part each of the zones makes up about one-fifth of the total width. Zone I encompasses the median portion of the median eminence and the prominent long capillary loops of the deep vascular network (Duvernoy, '72). Zones IIIA and B form the medial face of the tuberoinfundibular sulci. Zones IIA and $\mathrm{B}$ lie in a paramedian position between Zone $\mathrm{I}$ and Zones IIIA and B.

\section{RESULTS}

\section{Organum vasculosum}

A small amount of somatostatin appeared in the OVLT of all but one of the animals studied. Generally it was located in nervous tissue external to the component capillaries (fig. 2). Less commonly bodies ${ }^{*}$ that labeled for somatostatin were found in rather large aggregations. The probable intracellular position of these masses could not be defined accurately with the light microscope; they always seemed to be surrounded by capillaries of the organum vasculosum.

\section{Median eminence and infundibular stem}

At the anterior extremity of the median eminence, whether or not the pars tuberalis was present, somatostatin formed a prominent transverse band (fig. 3). Also, bodies labeled for somatostatin were scattered through the tissue intervening between this band and the third ventricle.

In the central wide segment of the median eminence somatostatin was highly concentrated (figs, $1,4,5$ ), this accumulation being most prominent in zones IIA and B. Most granules or bodies that labeled for somatostatin were located in the superior portion of the external lamina (figs. 13, 14); they extended on into the internal lamina in a dispersed arrangement and sometimes reached the ependymal layer (figs. 4, 13). The inferior portion of the external lamina contained far less somatostatin; here somatostatin seemed to be located in occasional axons that extended downward toward the primary vascular plexus (figs. 13, 14).

Zone I contained less somatostatin than did zones IIA and B (figs. 1, 4). Here the general arrangement of somatostatin was less regular because of invasion of the median eminence by long capillary loops of the primary plexus. Somatostatin occurred chiefly around the periphery of these capillaries and labeled bodies were scattered up to the third ventricle (fig. 4). The lateral zones IIIA and B varied the most in somatostatin content and were usually character. ized by a gradual reduction in the amount of somatostatin toward the lateral border of the median eminence (figs. 1, 12). Thus, the deepest part of the tuberoinfundibular sulcus represented the approximate lateral boundary of the area for somatostatin localization in the median eminence.

When viewed at high magnification, the bodies that labeled for somatostatin were

4 The term "body" refers to individual structural units that bore the DAB label for somatostatin. As described in the text, these structures varied a great deal in form when viewed at high magnification. 


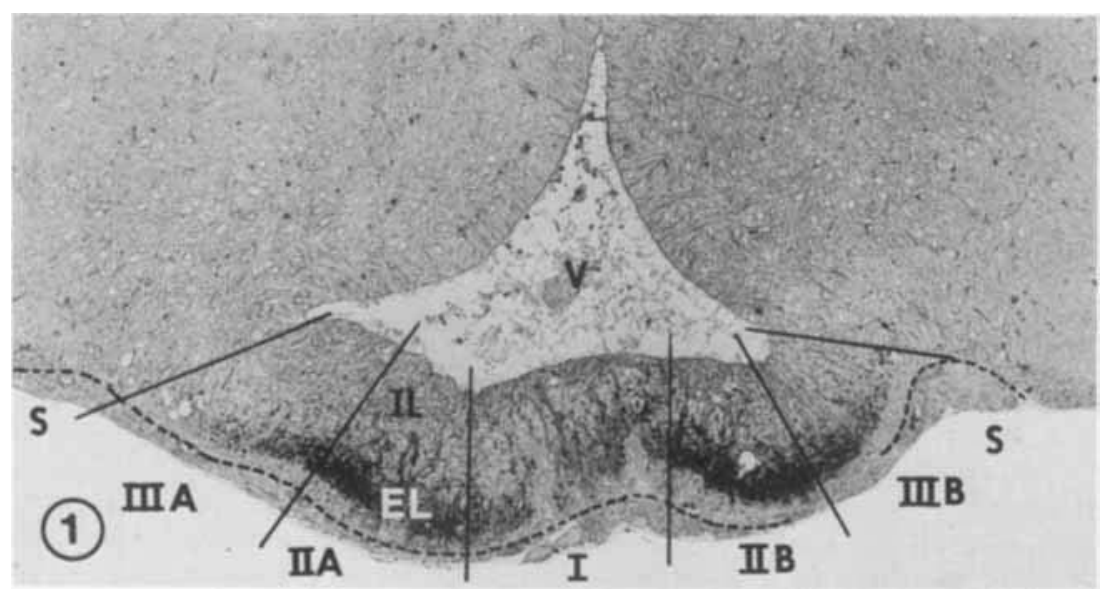

Fig. 1 A transverse section through the broad central segment of the median eminence from a male rat labeled for somatostatin. Illustrated is the zonation of the median eminence based on the concentration and arrangement of somatostatin. Zone I: median region with somatostatin distributed sparsely through both internal (IL) and external (EL) laminae in association with deep capillaries of the primary plexus. Zones IIA and $B$ : bilateral regions of maximal hormone concentration. Zones IIIA and B: bilateral zones of decreasing somatostatin concentration along the medial side of the tuberoinfundibular sulci ( $S$ ). The interrupted line marks the boundary between the median eminence above and the hypophysial pars tuberalis below. V, third ventricle. $\times 110$.

most often granules of varied shape and size (fig. 14). They accumulated in loose aggregations; less commonly these groups appeared to be encompassed by a membrane. The latter arrangement, and the frequent rows of bodies, suggested the presence of somatostatin in axons. No general labeling of cytoplasm in tanycyte processes was observed (figs. 12, 13). Nevertheless, the bodies described above were often associated closely with tanycytes and ependymal cell bodies where their position seemed to be external to the tanycytes.

From the dorsal side of the infundibulum, at its junction with the floor of the brain (fig. 9), somatostatin continued caudally for a short distance in the median eminence as a broad band near the ventral surface of the brain (fig. 6). Finally, it was absent from the floor of the inframammillary recess.

The high concentration of somatostatin in the central segment of the median eminence continued caudally into the infundibulum where it was present throughout the nervous tissue facing the hypophysial pars tuberalis (fig. 6). In such sections the lesser concentration of somatostatin in zone I of the median eminence was still evident in the ventromedial region of the infundibulum. With closure of the infundibular recess to form the infundibular stem, a considerable amount of somatostatin also extended into the stem (fig. 9). Thus, at least the proximal one-quarter of the infundibular stem contained a large amount of somatostatin (fig. 7). Somatostatin was also present in small amounts throughout the distal portion of the stem as far as its continuation into the pars nervosa (figs. $8,9)$.

No differences between males and females have been found in the amount or arrangement of somatostatin in the median eminence and infundibular stem.

\section{Hypothalamic nuclei}

The demonstration of somatostatin in hypothalamic nuclei with antiserum B173 was not successful in all animals; it appeared in the ventromedial and/or dorsomedial (figs. 15, 16) hypothalamic nuclei of only one male and one female rat. Here somatostatin was associated with neuronal cell bodies or with the proximal portion of a broad process that appeared to be a dendrite. In some instances the label seemed to be distributed diffusely through a small 
area of the cytoplasm. Commonly the label was sufficiently localized to suggest its containment in an axon making a synapse with the cell body or dendrite. Scattered between the cell bodies were labeled structures that appeared to be axons. Perikarya with the associated label constituted only a small portion of the cell bodies in these hypothalamic nuclei. Prior absorption of the antiserum with somatostatin eliminated all labeling within these hypothalamic nuclei.

\section{Other circumventricular organs}

As did Pelletier et al. ('74,'75) we observed some deposition of oxidized $\mathrm{DAB}$ to be associated with the walls of capillaries in the peripheral region of the epiphysis. Since the deposit usually appeared to be extracellular, was exceedingly variable in amount within an individual gland, and from animal to animal, these observations are difficult to understand. The subfornical body was not examined thoroughly and somatostatin was never observed in the high columnar epithelium of the subcommissural organ in contrast to the reports of Pelletier et al. ('74, '75).

\section{DISCUSSION}

The validity of our observations on localization of somatostatin is dependent on the purity of the hormonal preparation used for immunization. We do not have conclusive evidence in this regard and, hence, there may be some doubt regarding specificity of our antiserum. The possibilities that the somatostatin preparation used for immunization contains more than one compound and that our antiserum may cross-react with unknown compounds must be kept in mind. One's confidence that antiserum B173 does reveal somatostatin when used immunocytochemically is enhanced by several arguments. First, the utility of the antiserum for labeling the hypothalamus was destroyed by prior absorption with synthetic somatostatin but not by $a b-$ sorption with TRH, GnRH, vasopressin or oxytocin. Second, with regard to immunohistochemical ${ }^{5}$ localization of somatostatin in the brain, the observations made by Hökfelt et al. ('75), King et al. ('75), Pelletier et al. ('74, '75), and us in the rat, and by Hökfelt et al. ('74) and Dubé et al.
('75) in the guinea pig, reveal several points of agreement by some or all of these investigators. In both species somatostatin is highly concentrated in the median eminence and also occurs in the organum vasculosum of the lamina terminalis. Also, somatostatin is found throughout the length of the infundibular stem, this feature having been observed by Hökfelt et al. ('74) and Dubé et al. ('75) in the guinea pig, and by Hökfelt et al. ('75) and us in the rat. Further with immunohistological methods, somatostatin is demonstrated in structures that appear to be axons.

A third basis for confidence in the conclusion that we have demonstrated somatostatin is the agreement between our observations on the distribution of somatostatin with those of Krulich et al. ('72) who employed bioassay to determine the amount of somatostatin in sections of hypothalamus cut in several planes. Plots of their data showed that somatostatin-like activity was greatest in the median eminence and was also present in a region dorsal to the optic chiasma that probably included the OVLT. Confirmatory also are the reports by Brownstein et al. (75) and Patel et al. (75) that quantification with radioimmunoassay shows more somatostatin to be present in the median eminence than in any other part of the hypothalamus. Further, these workers agree that somatostatin occurs in the ventromedial nucleus.

On the contrary, other observations bearing on the localization of somatostatin are discordant and, therefore may arouse concern regarding the reliability of our results. The reasons for these differences are not now apparent. Thus, in their immunohistological studies Pelletier et al. ('74, '75) and King et al. (75) working with the rat, and Hökfelt et al. (74) and Dubé et al. ('75) with the guinea pig, did not find the hormone in perikarya of any nerve cells. Our finding of somatostatin in close association with perikarya of the ventromedial and/or dorsomedial nucleus of two rats raises the possibility that it is located within the cell cytoplasm. Confirmation of this assumption will require the use of electron microscopy. The failure of immunohistochemists

\footnotetext{
5 "Immunohistological" is used to encompass both immunofluorescence and immunocytochemistry.
} 
to demonstrate somatostatin consistently in neuronal perikarya may arise from irregular dissolution of the small amounts of hormone that may be present there. Elde and Parsons (75) implanted the $\mathrm{MtTW}_{15}$ mammosomatotropic tumor into rats in order to elevate the serum level of circulating growth hormone and thus stimulate somatostatin-secreting neurons. This procedure enabled them to demonstrate somatostatin in perikarya of the hypothalamic periventricular nucleus with immunocytochemistry. Hökfelt et al. ('75) reported weak immunofluorescence for somatostatin in a few nerve cell bodies in the anterior periventricular region of the rat hypothalamus. Their evidence does not indicate clearly whether the fluorescence was in perikaryonal cytoplasm or in associated axons.

Also of concern is the study of Brownstein et al. ('75) who, with radioimmunoassay, detected widespread distribution of somatostatin in the hypothalamus. They reported its presence in the periventricular, arcuate, medial preoptic and ventral premammillary nuclei where it has not been demonstrated by immunocytochemistry. Because of the peculiar shape of the arcuate nucleus, and its probably intermingling with somatostatin-laden axons entering the median eminence, a clean separation of the two structures by the punch technique used by Brownstein et al. seems impossible. Further Brownstein et al. ('75) found somatostatin throughout the brain at levels one-third to one-tenth the amount in the hypothalamus; only $20 \%$ of the total hypothalamic content was present in the median eminence. Some immunocy tochemists (e.g., Hökfelt et al., "75) have found somatostatin-like substances in diverse cell types of numerous other organs. An explanation for the differences in observations pertaining to the distribution of somatostatin in the body is not now apparent, and suggest that it may play a much broader role than serving only as a hypophysiotropic hormone.

In contrast to the situation with somatostatin, rather close agreement exists between the data on distribution of GnRH as determined by assay and immunocytochemistry of brain tissue. Thus the localization of $\mathrm{GnRH}$ as indicated by bioassay
(Crighton et al., '70) and radioimmunoassay (Palkovits et al., '74) is quite similar to that concluded from immunocytochemistry, as will be described subsequently.

\section{Comparative distribution of somatostatin and GnRH}

It is important to know if the distributions of the various hypophysiotropic hormones in the brain are the same or different. The occurrence of significant differences would suggest that the methods used for demonstration of them are specific. Further, different patterns of distribution would suggest the existence of unique neural pathways for regulating the secretion of each hormone. In the case of somatostatin and GnRH immunocytochemical findings show that significant similarities and differences exist in their localizations in the rat brain. With respect to the OVLT, both hormones appear to occur in axons surrounding its capillaries. However, GnRH (Baker et al., '75) is much more bountiful and more widely distributed. In the median eminence the pattern of distribution for the hormones is strikingly different. GnRH (King et al., '74; Baker et al., '74, '75; Kordon et al., '74; Sétáló et al., '75) appears as a flat band that extends across the midline at the cephalic and caudal extremities. Throughout the remaining major extent of the median eminence, the location of most GnRH diverges into bilateral longitudinal bands underlying the tuberoinfundibular sulci, with the highest concentration occurring at the caudal side of the junction of infundibulum with hypothalamus in association with the tuberoinfundibular sulci. In contrast, somatostatin forms a band, with variations in density, that extends across the full width of the median eminence and throughout its entire length. Further, while foci of GnRH are scattered dorsomedially from the tuberoinfundibular sulci as far as the ependymal layer, somatostatin is more common in the superior part of zone II.

There is a difference in the form of the bodies that label for GnRH and somatostatin. Most bodies labeled for GnRH resemble sharply circumscribed beads or membrane-enclosed structures with a granular interior. On the other hand those that contain somatostatin are usually granules 
of varied shape and size, and rarely appear as an aggregation of granules surrounded by a membrane.

The distributions of somatostatin and $\mathrm{GnRH}$ differ markedly in the infundibular stem. GnRH is found only on the dorsolateral sides of the infundibular stem at its junction with the hypothalamus in association with the tuberoinfundibular sulci and nowhere else in the stem. In contrast, somatostatin appears as a prominent feature throughout the outer zone of the stem in its proximal quarter, and is found in lesser amount throughout the distal portion of the stem.

The areas occupied by $\mathrm{GnRH}$ and somatostatin overlap in the external lamina along the medial side of the tuberoinfundibular sulci. GnRH occurs also over the deepest part of each sulcus and along its dorsolateral side; somatostatin is rarely so positioned, except to a minor degree at the caudal side of the junction of infundibulum with the hypothalamus.

Thus, the median eminence and proxi$\mathrm{mal}$ infundibulum are the major sites for accumulation of somatostatin. The functional relationship of somatostatin in hypothalamic nuclei to accumulations in the median eminence is not clear. The recently demonstrated presence of somatostatin in the stomach, intestine and pancreas (Arimura et al., '75; Hökfelt et al., '75) and its capacity to inhibit secretion of glucagon, insulin and gastrin suggest that it plays a broader physiologic role than to serve only as a hypophysiotropic hormone.

\section{LITERATURE CITED}

Arimura, A., H. Sato, A. Dupont, N. Nishi and A. V. Schally 1975 Somatostatin: abundance of immunoreactive hormone in rat stomach and pancreas. Science, 189: 1007-1009.

Baker, B. L., W. C. Dermody and J. R. Reel 1974 Localization of luteinizing hormone-releasing hormone in the mammalian hypathalamus. Am. J. Anat., 139: 129-134.

1975 Distribution of gonadotropin-releasing hormone in the rat brain as observed with immunocy tochemistry. Endocrinology, 97: 125-135.

Brazeau, P., W. Vale, R. Burgus, N. Ling, M. Butcher, J. Rivier and R. Guillemin 1973 Hypothalamic polypeptide that inhibits the secretion of immunoreactive pituitary growth hormone. Science, 179: 77-79.

Brownstein, M., A. Arimura, H. Sato, A. V.
Schally and J. S. Kizer 1975 The regional distribution of somatostatin in the rat brain. Endocrinology, 96: 1456-1461.

Crighton, D. B., H. P. G. Schneider and S. M. McCann 1970 Localization of LH-releasing factor in the hypothalamus and neurohypophysis as determined by an in vitro method. Endocrinology, 87: 323-329.

Dubé, D., R. Leclerc, G. Pelletier, A. Arimura and A. V. Schally 1975 Immunohistochemical detection of growth hormone-release inhibiting hormone (somatostatin) in the guinea-pig brain. Cell Tiss. Res., 161: 385-392.

Duvernoy, H. 1972 The vascular architecture of the median eminence. In: Brain-Endocrine Interaction. Median Eminence: Structure and Function. K. M. Knigge, D. E. Scott and A. Weindl, eds. S. Karger, New York, pp. 79108.

Elde, R. P., and J. A. Parsons 1975 Immunocytochemical localization of somatostatin in cell bodies of the rat hypothalamus. Am. J. Anat, 144: 541-548.

Hökfelt, T., S. Efendić, C. Hellerström, O. Johansson, R. Luft and A. Arimura 1975 Cellular localization of somatostatin in endocrine-like cells and neurons of the rat with special references to the $A_{1}$-cells of the pancreatic islets and to the hypothalamus. Acta Endocrinologica, 80: (suppl. 200): 5-40.

Hökfelt, T., S. Efendić, O. Johansson, R. Luft and A. Arimura 1974 Immunohistochemical localization of somatostatin (growth hormone release-inhibiting factor) in the guinea pig brain. Brain Res., 80: 165-169.

King, J. C., A. A. Gerall, J. B. Fishback, K. E. Elkind and A. Arimura 1975 Growth hormone-release inhibiting hormone (GH-RIH) pathway of the rat hypothalamus revelaed by the unlabeled antibody peroxidase-antiperoxidase method. Cell Tiss. Res., 160: 423-430.

King, J. C., J. A. Parsons, S. L. Erlandsen and $T$. H. Williams 1974 Luteinizing hormonereleasing hormone (LH-RH) pathway of the rat hypothalamus revealed by the unlabeled antibody peroxidase-antiperoxidase method. Cell Tiss. Res., 153: 211-217.

Kordon, C., B. Kerdelhué, E. Pattou and M. Jutisz 1974 Immunocytochemical localization of LHRH in axons and nerve terminals of the rat median eminence. Proc. Soc. Exp. Biol. Med., 147: $122-127$.

Krulich, L., P. Illner, C. P. Fawcett, M. Quijada and S. M. McCann 1972 Dual hypothalamic regulation of growth hormone secretion. In: Growth and Growth Hormone. A. Pecile and E. E. Müller, eds. Excerpta Med. Int. Congr. Ser. No. 244, Excerpta Medica, Amsterdam, pp. 306-316.

Palkovits, M., A. Arimura, M. Brownstein, A. V. Schally and J. M. Saavedra 1974 Luteinizing hormone-releasing hormone (LH-RH) content of the hypothalamic nuclei in rat. Endocrinology, 95: 554-558.

Patel, Y. C., G. C. Weir and S. Reichlin 1975 Anatomic distribution of somatostatin (SRIF) in brain and pancreatic islets as studied by 
radioimmunoassay (RIA). 57th Annual Meeting, The Endocrine Soc., June 18-20, 1975, New York City, p. 127.

Pelletier, G., F. Labrie, A. Arimura and A. V. Schally 1974 Electron microscopic immunohistochemical localization of growth hormonerelease inhibiting hormone (somatostatin) in the rat median eminence. Am. J. Anat., 140: 445-450.

Pelletier, G., R. Leclerc, D. Dubé, F. Labrie, R. Puviani, A. Arimura and A. V. Schally 1975 Localization of growth hormone-release-inhibiting hormone (somatostatin) in the rat brain. Am. J. Anat, 142: 397-401.

Petrali, J. P., D. M. Hinton, G. C. Moriarty and L. A. Sternberger 1974 The unlabeled antibody enzyme method of immunocytochemistry. Quantitative comparison of sensitivities with and without peroxidase-antiperoxidase complex. J. Histochem. Cytochem., 22: 782-801.

Sétáló, G., S. Vigh, A. V. Schally, A. Arimura and B. Flerkó 1975 LH-RH-containing neural elements in the rat hypothalamus. Endocrinology, 96: 135-142.

Sternberger, L. A., P. H. Hardy, Jr., J. J. Cuculis and H. G. Meyer 1970 The unlabeled antibody enzyme method of immunohistochemistry. Preparation and properties of soluble antigenantibody complex (horseradish peroxidase-antihorseradish peroxidase) and its use in identification of spirochetes. J. Histochem. Cytochem., 18: $315-333$.

Vaitukaitis, J., J. B. Robbins, E. Nieschlag and G. T. Ross 1971 A method for producing specific antisera with small doses of immunogen. J. Clin. Endocr., 33: 988-991.

PLATE 1

EXPLANATION OF FIGURES

All illustrations on plates $1-3$ are of female rats except figure 9 which represents a male. On this plate are transverse sections from rats labeled for somatostatin. Figures $3-8(\times 110)$ are successive sections that show the distribution of somatostatin from the anterior to the posterior end of the median eminence and from the proximal to the distal portion of the infundibular stem. The interrupted line marks the boundary between median eminence or infundibulum above and pars tuberalis below.

2 Organum vasculosum of the lamina terminalis. Bodies (short arrows) labeled for somatostatin are scattered sparsely in the nervous tissue outside the capillaries (C). A dense aggregation of such bodies (long arrow) is shown also. OC, optic chiasma. $\times 250$.

3 Cephalic end of the median eminence. Somatostatin-labeled bodies (arrows) have accumulated in the dorsal area of the external lamina (EL) and are scattered in the internal lamina (IL) which intermingles with the arcuate nucleus (AN). $\mathrm{V}$, ventricle.

4 Broad central segment of the median eminence. In zone I bodies containing somatostatin border several deep capillaries (arrows) of the primary plexus. V, ventricle.

5 Median eminence with deepening tuberoinfundibular sulci at the sides. Somatostatin extends to the apices of the sulci. V, ventricle; IL, internal lamina; EL, external lamina; $S$, tuberoinfundibular sulcus.

6 The infundibulum caudal to its site of separation from the median eminence (ME) contains a great deal of somatostatin (arrows). In the median eminence somatostatin forms a ventral transverse band. IR, infundibular recess.

7 Proximal infundibular stem contains much somatostatin peripherally except for the ventromedial region.

8 Caudal infundibular stem near the hypophysis. A small amount of somatostatin (arrows) is still present peripherally. 

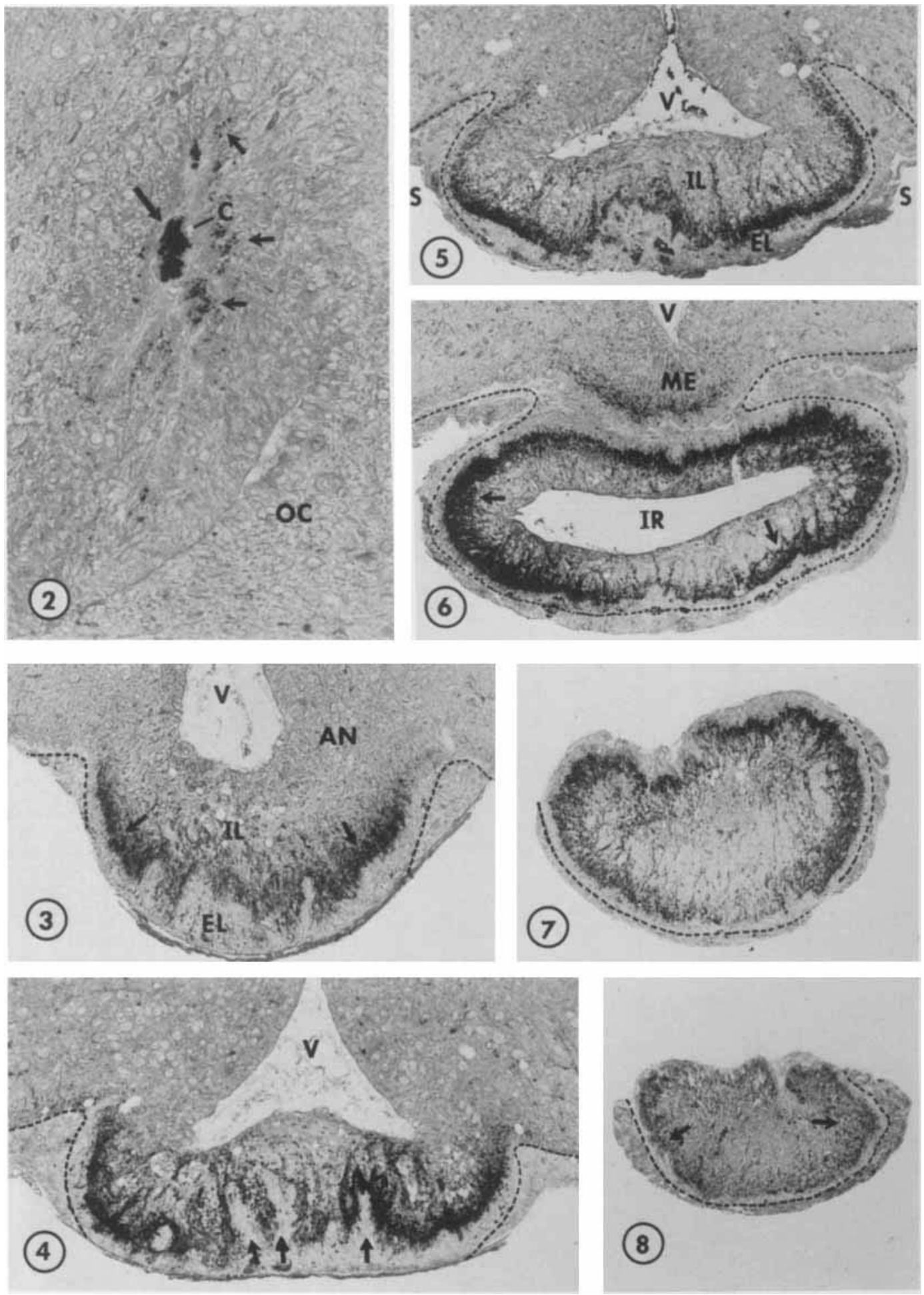


\section{PLATE 2}

EXPLANATION OF FIGURES

In figures 10-12 the pars tuberalis is external to the interrupted line.

9 A montage of a sagittal section through the median eminence and infundibular stem labeled for somatostatin. The numbers indicate the approximate levels of other jllustrated transverse sections. Somatostatin (short arrows) is concentrated in the dorsal region of the external lamina (EL) throughout the median eminence. Much is also present on the dorsal side of the proximal infundibular stem (long arrows) and in the contiguous median eminence (double arrow). The caudal portion of the stem contains only a small amount of somatostatin. $\mathrm{H}$, hypophysis; $\mathrm{V}$, third ventric]e; IL, internal lamina. $X 100$.

10 A transverse section through the junction of the infundibuiar stem and median eminence showing the location of somatostatin (arrows) peripherally in the infundibulum (I) and the continuity of its distribution into the median eminence (ME). $\mathrm{S}$, tuberoinfundibular sulcus. $\times 110$.

11 A control scction adjacent to that shown in figure 10. Labeling for somatostatin did not occur because the antiserum B173 was absorbed previously with somatostatin. I, infundibular stem; V, ventricle. $\times 110$.

12 Zones II and III of the median eminence labeled for somatostatin. Somatostatin (dark granules) is concentrated in the superior part of the external lamina (EL). Somatostatin fades out at the summit of the tuberoinfundibular sulcus (S). Labeled bodies lie alongside tanycyte ( $T$ ) processes. IR, infundibular recess; El, external lamina; $T$, pars tuberalis. $\times 250$. 


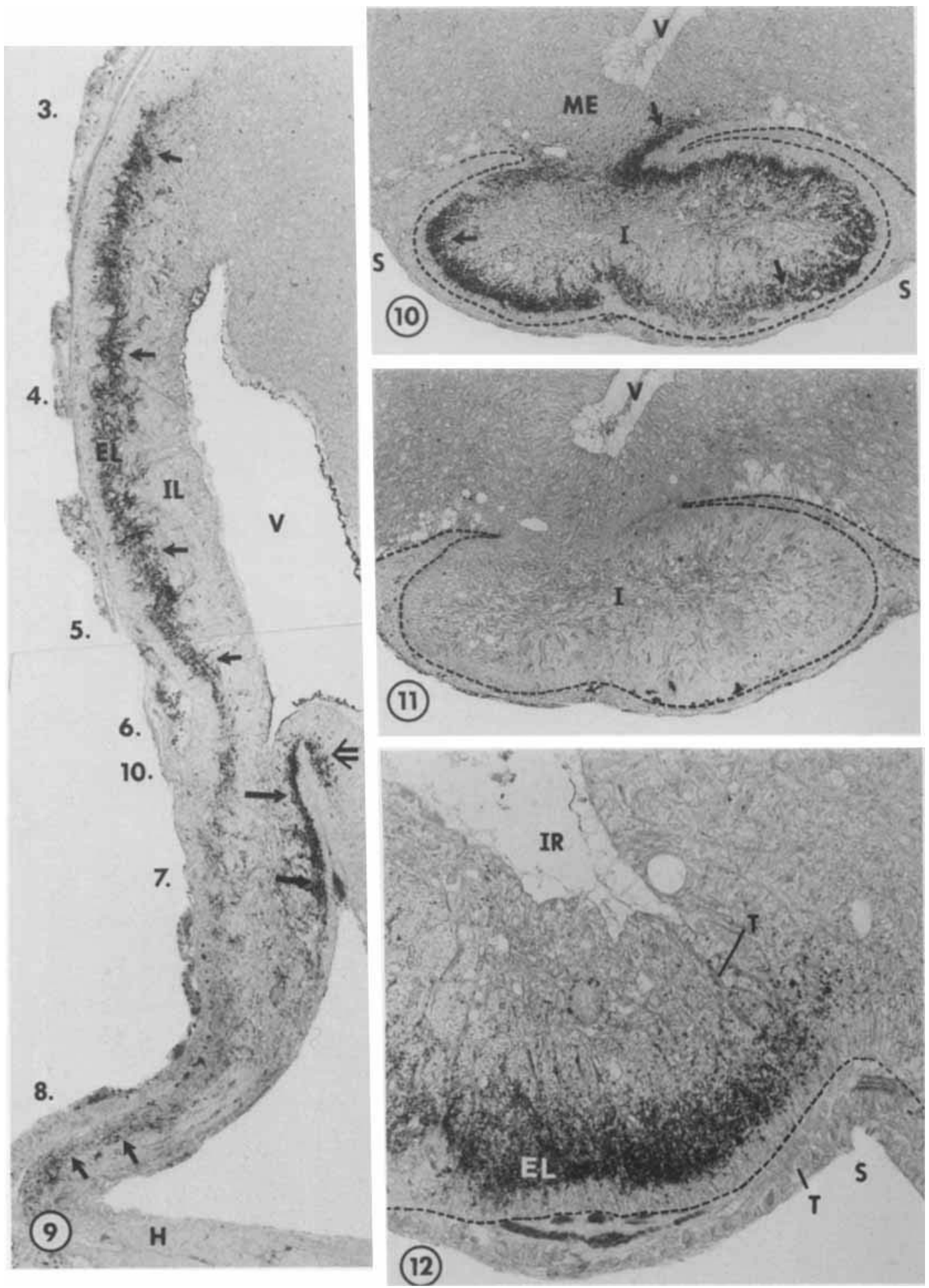


PLATE 3

EXPLANATION OF FIGURES

All specimens illustrated on this plate were labeled for somatostatin.

13 Zone II of the median eminence; the major accumulation of the hormone is in the superior part of the external lamina (EL). The jnferior portion of the external lamina contains little somatostatin. Some rows of bodies labeled with DAB (long arrows) extend downward toward the primary plexus (PP). Somatostatin is scattered in the internal lamina and seems to lie alongside tanycyte processes. IR, infundibular recess; IL, internal lamina. $\times 250$.

14 Zone II of the median eminence magnified to show the shapes of the somatostatinlabeled bodies. Most are granules of varied shapes and sizes. Others are aggregates of granules and may be membrane-enclosed (arrows). $\times 1,000$.

15 Centrally is a perikaryon from the dorsomedial hypothalamic nucleus, with two areas of the cytoplasm labeling for somatostatin. The arrows indicate three foci of somatostatin that are probably axons. $\times 480$.

16 Several neuronal cell bodies of the dorsomedial nucleus that illustrate different patterns of oxidized DAB deposition: (A) cells with sharply circumscribed areas that might represent axonal terminations; (B) cells with more diffuse deposition in a restricted part of the cell; and (C) deposition of DAB on the proximal part of a cell process. $\times 480$. 

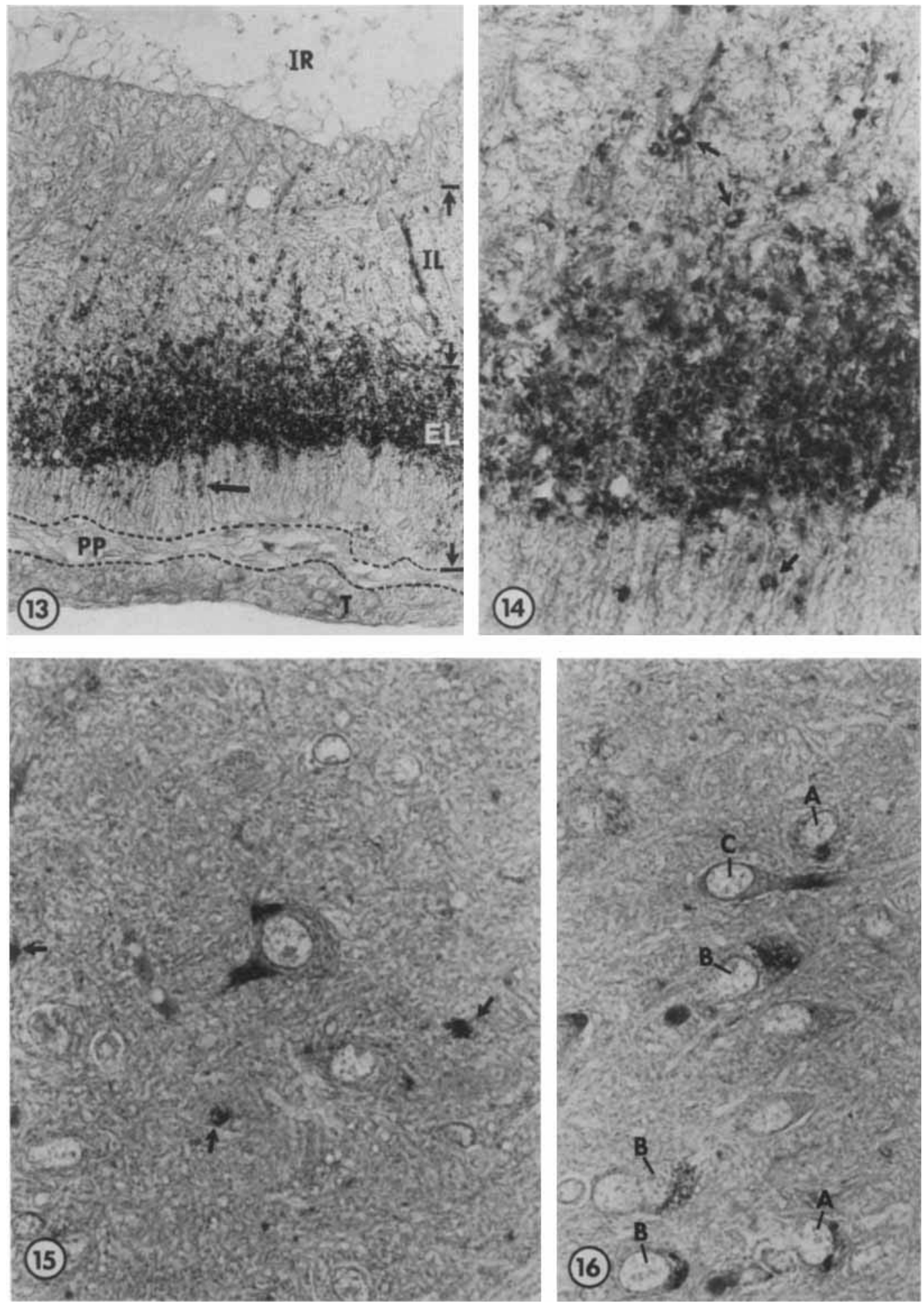